\title{
Managing chronic pain in elderly patients requires a CHANGE of approach
}

\section{Kress, Hans-Georg}

2014-06

Kress , H-G , Ahlbeck, K, Aldington, D , Alon , E , Coaccioli , S , Coluzzi , F , Huygen , F , Jaksch , W , Kalso , E , Kocot-Kepska, M , Mangas , A C , Margarit Ferri , C, Morlion , B , Mueller-Schwefe, G, Nicolaou , A, Perez Hernandez , C, Pergolizzi , J , Schaefer , M \& Sichere , P 2014 , ' Managing chronic pain in elderly patients requires a CHANGE of approach ' , Current Medical Research and Opinion , vol. 30 , no. 6 , pp. 1153-1164 . https://doi.org/10.1185/030079

http://hdl.handle.net/10138/159372

https://doi.org/10.1185/03007995.2014.887005

publishedVersion

Downloaded from Helda, University of Helsinki institutional repository.

This is an electronic reprint of the original article.

This reprint may differ from the original in pagination and typographic detail.

Please cite the original version. 


\title{
Current Medical Research and Opinion
}

\section{Managing chronic pain in elderly patients requires a CHANGE of approach}

\author{
Hans-Georg Kress, Karsten Ahlbeck, Dominic Aldington, Eli Alon, Stefano \\ Coaccioli, Flaminia Coluzzi, Frank Huygen, Wolfgang Jaksch, Eija Kalso, \\ Magdalena Kocot-Kępska, Ana Cristina Mangas, Cesar Margarit Ferri, Bart \\ Morlion, Gerhard Müller-Schwefe, Andrew Nicolaou, Concepción Pérez \\ Hernández, Joseph Pergolizzi, Michael Schäfer \& Patrick Sichère
}

To cite this article: Hans-Georg Kress, Karsten Ahlbeck, Dominic Aldington, Eli Alon, Stefano Coaccioli, Flaminia Coluzzi, Frank Huygen, Wolfgang Jaksch, Eija Kalso, Magdalena KocotKępska, Ana Cristina Mangas, Cesar Margarit Ferri, Bart Morlion, Gerhard Müller-Schwefe, Andrew Nicolaou, Concepción Pérez Hernández, Joseph Pergolizzi, Michael Schäfer \& Patrick Sichère (2014) Managing chronic pain in elderly patients requires a CHANGE of approach, Current Medical Research and Opinion, 30:6, 1153-1164, DOI: $10.1185 / 03007995.2014 .887005$

To link to this article: http://dx.doi.org/10.1185/03007995.2014.887005

Accepted author version posted online: 23 Jan 2014.

Published online: 06 Mar 2014.

LII Article views: 1205

View Crossmark data $₫$

Submit your article to this journal

View related articles $\asymp$

Citing articles: 1 View citing articles $\llbracket$ 


\section{Commentary \\ Managing chronic pain in elderly patients requires a CHANGE of approach}

\author{
Hans-Georg Kress \\ Medizinische Universität/AKH Wien, Vienna, Austria \\ Karsten Ahlbeck \\ Capio S:t Göran Hospital, Stockholm, Sweden \\ Dominic Aldington* \\ Churchill Hospital, Oxford, UK \\ Eli Alon \\ Universitätsspital Zurich, Zurich, Switzerland \\ Stefano Coaccioli \\ Santa Maria General Hospital, Terni, Italy
}

Flaminia Coluzzi

Department of Anesthesia, Intensive Care and Pain

Therapy, Sapienza University of Rome, Italy

Frank Huygen

University Hospital, Rotterdam, The Netherlands

\section{Wolfgang Jaksch}

Schmerzambulanz, Wilhelminenspital der Stadt Wien, Austria

\section{Eija Kalso}

Helsinki University Central Hospital, Finland

\section{Magdalena Kocot-Kępska}

Poradnia Leczenia Bólu University Hospital, Kraków, Poland

\section{Ana Cristina Mangas \\ Hospital de Santo André, Leiria, Portugal}

Cesar Margarit Ferri

Hospital General Universitario de Alicante, Spain

\section{Bart Morlion}

University Hospitals Leuven, Belgium

\section{Gerhard Müller-Schwefe}

Schmerz- und Palliativzentrum, Göppingen, Germany

\section{Andrew Nicolaou}

St. Georges Hospital, London, UK

\section{Concepción Pérez Hernández}

Hospital Universitario de la Princesa, Madrid, Spain

\section{Abstract}

In many countries, the number of elderly people has increased rapidly in recent years and this is expected to continue; it has been predicted that almost a quarter of the population in the European Union will be over 65 years of age in 2035. Many elderly people suffer from chronic pain but it is regularly under-treated, partly because managing these patients is often complex. This paper outlines the extent of untreated pain in this population and the consequent reduction in quality of life, before articulating the reasons why it is poorly or inaccurately diagnosed. These include the patient's unwillingness to complain, atypical pain presentations, multiple morbidities and cognitive decline. Successful pain management depends upon accurate diagnosis, which is based upon a complete history and thorough physical examination, as well as an assessment of psychosocial functioning. Poor physician/patient communication can be improved by using standardized instruments to establish individual treatment targets and measure progress towards them. User-friendly observational instruments may be valuable for patients with dementia. In line with the widely accepted biopsychosocial model of pain, a multidisciplinary approach to pain management is recommended, with pharmacotherapy, psychological support, physical rehabilitation and interventional procedures available if required. Declining organ function and other physiological changes require lower initial doses of analgesics and less frequent dosing intervals, and the physician must be aware of all medications that the patient is taking, in order to avoid drug/drug interactions. Non-adherence to treatment is common, and various strategies can be employed to improve it; involving the elderly patient's caregivers and family, using medication systems such as pill-boxes, or even sending text messages. In the long term, the teaching of pain medicine needs to be improved - particularly in the use of opioids - both at undergraduate level and after qualification.

\section{Introduction}

In the Western hemisphere, the elderly population has increased rapidly over past decades. For example, between 1960 and 1999 the proportion of the European population aged $\geq 60$ years rose from $16 \%$ to $21 \%$, while the proportion aged $\geq 80$ years doubled or even tripled in virtually every country ${ }^{1}$. This growth is expected to continue; across the 27 European Union member states, the European Commission predicts that almost a quarter of the population will be more than 65 years of age by $2035^{2}$ (Table 1 ). In the USA, people reaching 65 years of age can expect to live another 18.6 years ${ }^{3}$. Globally, approximately $10 \%$ of the world's population is currently aged $\geq 65$ years, but this is forecast to exceed $16 \%$ by $2050^{4}$.

Many elderly people experience chronic pain; the prevalence of chronic noncancer pain and neuropathic pain increase with age $\mathrm{e}^{5,6}$, and by the age of 70 years pain affects $79 \%$ of women and $53 \%$ of men ${ }^{7}$. Managing pain in these patients is often complex, because of declining organ function, increased vulnerability to adverse side effects, the presence of comorbidities, and multiple medications ${ }^{8}$. Atypical pain presentation and cognitive impairment may further complicate the picture. Today, pain is frequently under-treated in this age group ${ }^{9,10}$, yet the 


\section{Joseph Pergolizzi}

Department of Medicine, Johns Hopkins University School of Medicine, Baltimore, MD, USA

Naples Anesthesia and Pain Associates, Naples, FL, USA

\section{Michael Schäfer}

Department of Anaesthesiology and Intensive Care Medicine, Charité University Berlin, Campus Virchow Klinikum, Berlin, Germany

\section{Patrick Sichère}

Hôpitaux de Saint-Denis, Paris, France

\section{Address for correspondence:}

Joseph Pergolizzi MD, Professor, Naples Anesthesia and Pain Associates, 4840 Sycamore Drive, Naples, FL 34119, USA.

Tel.: +1 239597 3564; Fax: +1 239597 7566; jpjmd@msn.com

\section{Keywords:}

Adherence - Chronic pain - Declining organ function - Education - Multi-disciplinary approach Physician/patient communication - Under-treatment

Accepted: 14 January 2014; published online: 6 March 2014 Citation: Curr Med Res Opin 2014: 30:1153-64 demand for satisfactory pain management is increasing dramatically and will continue to do so.

The CHANGE PAIN initiative was established in 2009 to increase the understanding of chronic pain among healthcare professionals, to identify best practice in pain management, and to provide guidance on the treatment of patients with pain. The international CHANGE PAIN Advisory Board is composed of pain specialists from Europe and the USA, who were selected on the basis of their research activity and considerable clinical experience. At meetings on 9th and 10th December 2011, and 30th and 31st March 2012, Board members considered issues related to the incidence, diagnosis and treatment of elderly patients with pain, and discussed possible ways of improving current clinical practice.

\section{Unmet needs}

Pain is one of the most prevalent symptoms in elderly people; chronic pain is reported by approximately $60 \%$ of people aged 75 and over in the $\mathrm{UK}^{5}$. However, studies have consistently shown high levels of untreated or undertreated pain in this age group ${ }^{11}$. A recent systematic review of 64 studies found that the prevalence of chronic pain (i.e. of at least 3 months' duration) in older people living in the community ranged from $25 \%$ to $76 \%$, and in older people living in residential care ranged from $83 \%$ to $93 \%{ }^{12}$. A 2010 study by Smith et al. found that unrelieved pain of at least moderate severity was experienced by a quarter $(26 \%)$ of older adults (mean age 76 years) during the last 2 years of life, and this increased to nearly a half (46\%) during the last month of life, regardless of the cause of death ${ }^{13}$.

\section{Consensus point}

Pain is frequently untreated or under-treated in the elderly population.

\section{Consequences of unmet needs}

This under-treatment of pain has numerous consequences, many of which contribute to a reduced quality of life. Chronic pain patients exhibit significantly more mental distress than healthy controls, both when measured by self-rating and by professional assessment ${ }^{14}$. Cognitive performance may be affected by sleep disturbances and impaired emotional decision-making ${ }^{15,16}$, as a result of structural changes and behavioral deficits in cortical areas of the brain caused by chronic pain ${ }^{17}$. Many people with chronic pain report that it severely affects their ability to exercise, walk, carry out household chores and maintain an independent lifestyle ${ }^{18}$. The fact that patients with chronic pain are significantly more fatigued than healthy controls ${ }^{19}$ often leads to a decline in communal activities and social isolation. The resultant loneliness is one of the main factors leading to depression ${ }^{20}$, and these individuals experience higher levels of chronic pain than those who receive adequate social support ${ }^{21}$. In the elderly, the impact of these limitations is often greater, and may be compounded by a heavier burden being imposed upon caregivers.

\section{Pain in the elderly: Europe today}

The National Health and Wellness Survey (NHWS) is an internet-based, crosssectional study of the healthcare attitudes, behaviors and characteristics of the
*Current address: Hampshire Hospitals NHS Trust, Winchester, UK 
Table 1. Projected population of the 27 European Union member states ${ }^{2}$.

\begin{tabular}{cccccccc}
\hline & \multicolumn{3}{c}{ Percentage aged $65+$} & & \multicolumn{3}{c}{ Percentage aged $80+$} \\
\cline { 2 - 3 } & 2008 & 2035 & 2060 & & 2008 & 2035 & 2060 \\
\hline EU27 & 17.1 & 25.4 & 30.0 & & 4.4 & 7.9 & 12.1 \\
\hline
\end{tabular}

adult population in various countries, which is regularly conducted by Kantar Health of Princeton, New Jersey, USA. Core reports are produced for each country and the data obtained are analyzed according to a range of different parameters. The present analysis is based on the 2010 NHWS for the United Kingdom, France, Spain, Germany and Italy. The results are not inconsistent with previous estimates of the prevalence of pain in a much broader range of countries, but direct comparisons are difficult because different study designs, assessment methods and definitions of pain have been employed.

The prevalence of pain categorized as moderate or severe was highest in the 40-59 year age group, and mild pain was most common in the 18-39 year age group ${ }^{22}$. Of the 9963 survey participants who were aged $>65$ years, 2083 (21\%) reported experiencing pain during the last month (Table 2$)^{22}$. The proportion of women with pain in this age group was more than twice as high as the proportion of men with pain $(68 \%: 32 \%)$. Of these older respondents with pain, the intensity was rated as severe, moderate or mild by $15 \%, 65 \%$ and $20 \%$, respectively. The prevalence of depression increased progressively with the severity of pain, but was much more common among respondents below the age of 65 years than those $>65$ years. The majority of respondents with moderate or severe pain were receiving prescription analgesics, but the proportions were higher in the older age group: $86 \%$ and $70 \%$ for those with severe and moderate pain, respectively, compared with $81 \%$ and $56 \%$, respectively, for the younger age group 22 .

\section{Healthy ageing}

Chronic pain is a substantial burden on individuals and society, has a major impact on healthy ageing, and incurs enormous costs for healthcare systems. A systematic literature review by Kleijnen Systematic Reviews Ltd, commissioned by Grünenthal $\mathrm{GmbH}$, found a clear correlation between the severity of pain and reduced quality of life $(\mathrm{QoL})^{23}$. Furthermore, it revealed that the prevention and treatment of chronic pain are likely to improve QoL and could increase healthy lifespan by 2 years, which is one objective of the European Union's Active and Healthy Ageing Partnership project. The European Federation of IASP Chapters (EFIC) recently called for European

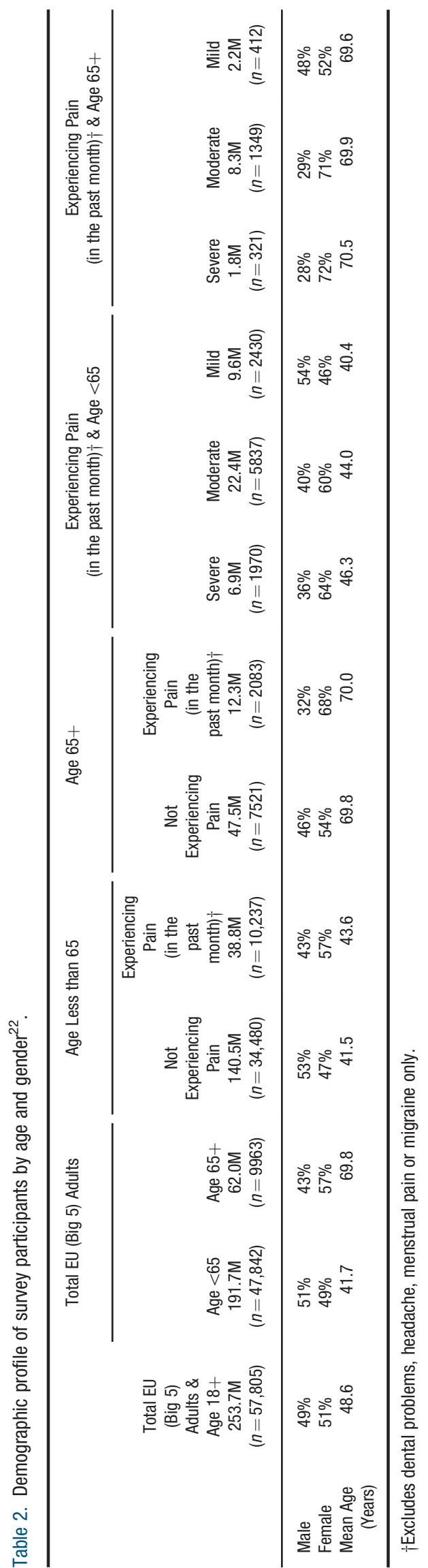

(C) 2014 Informa UK Ltd www.cmrojournal.com

Managing chronic pain in elderly patients Kress et al. 
governments and EU institutions to address the issues associated with untreated and undertreated pain, and this has since been endorsed by 58 organizations, including many national pain societies.

\section{The challenge of diagnosis}

There are various reasons why pain in elderly patients is often not diagnosed or inaccurately diagnosed. Firstly, they may fail to report their pain because they believe it is normal in old age, they are afraid it may lead to more diagnostic testing or loss of independence ${ }^{24,25}$, or because an accumulation of health-deteriorating factors means that a single factor (i.e. pain) gradually assumes a lower impact on self-rated health ${ }^{26}$. This unwillingness to complain may be compounded by the misconception among some healthcare professionals - for which there is no scientific basis - that the elderly have a reduced perception of pain compared with younger people ${ }^{25}$. Secondly, elderly patients - particularly those of most advanced age - may exhibit atypical pain presentations as a symptom of acute disease $^{27}$. Thirdly, multiple comorbidities are extremely common, and have a negative impact on patients' physical health and emotional, cognitive, and functional status ${ }^{28}$. For the clinician, comorbidities strongly influence the diagnostic process by modifying the presentation of coexistent conditions ${ }^{28}$. Fourthly, a particular problem is presented by patients whose capacity to communicate and remember has been reduced by cognitive decline, so that they are unable to provide an accurate picture of their symptoms. A further complication is that the brains of patients with Alzheimer's disease (AD), vascular dementia and frontotemporal dementia all exhibit atrophy and white matter lesions, but variations in severity and the areas affected mean that AD and frontotemporal dementia may be associated with increased levels of pain, but in vascular dementia these may be reduced ${ }^{29}$. Dementia is related to a lower prevalence of reported pain and analgesic use $\mathrm{s}^{30,31}$. The reasons for this are complex, but include the use of inadequate methods to assess and document pain, a reluctance to use opioids, and physicians' misunderstanding of the physiological and psychological components of pain ${ }^{32}$.

From the clinical perspective, one factor contributing to under-diagnosis may be that the International Classification Of Diseases-10 (ICD-10) - which serves as the worldwide basis for the classification of diagnoses does not include the diagnosis 'chronic pain'. Furthermore, if a patient presents with pain requiring medical attention, the physician has to search multiple categories of the ICD-10 to find an adequate diagnosis, and recognition of the uniqueness of pain conditions is a precondition for adequate treatment ${ }^{33}$.

\section{Consensus point}

There is a misconception among some healthcare professionals that elderly people have a reduced perception of pain and/or that pain is a normal consequence of ageing.

\section{Improving pain diagnosis in the elderly patient}

The complexity of pain assessment in elderly patients with chronic pain frequently requires a multidisciplinary approach to diagnosis. In particular, collaboration with a psychiatrist or psychologist has been recommended because of the possibility of depression, and also with a physical therapist, to help with functionality ${ }^{34}$.

The cornerstone of accurate diagnosis is a thorough examination that incorporates a complete history and physical examination, focusing on the patient's experience of pain. The location, character, frequency and intensity of the pain should be recorded, together with any exacerbating or alleviating factors and its effect on mood and sleep. Assessments should be made of any depression or cognitive impairment, the patient's gait and balance, and his or her level of physical functioning, as demonstrated by activities of daily living (ADLs). Psychosocial functioning can be estimated from the patient's relationship with relatives, social support groups and caregivers. The examination should be followed by any pertinent laboratory or diagnostic tests to identify the cause and subsequent pathophysiology of the pain. These investigations are important, because treatment strategies targeted at specific underlying mechanisms are likely to be most effective ${ }^{35}$.

\section{Standardized instruments}

In order to achieve a common understanding of the patient's pain experience - as well as the proposed therapy and expected outcome - effective physician/patient communication is essential. This communication is often compromised in elderly patients. Where this is the case, much valuable information can be obtained from caregivers and close relatives. Standardized instruments can improve communication and provide a greater insight into patients' pain. Unidimensional instruments such as the Numeric Rating Scale (NRS) and Visual Analogue Scale (VAS) can be used for many elderly patients, while more information can be obtained from multidimensional instruments. Examples of these include the McGill Pain Questionnaire (MPQ), which provides a quantitative measure of subjective pain experience from an intensity 
scale and three categories of word descriptors ${ }^{36}$, and the CHANGE PAIN Scale, which records not only the current and target pain intensity, but also the improvement required in six key parameters that affect $\mathrm{QoL}^{37}$. Patients differ enormously both in their symptoms and what they consider to be an acceptable level of pain; these instruments can help in establishing individual treatment targets and measuring progress towards them ${ }^{37}$.

\section{Patients with dementia}

In patients with advanced dementia, an inability to communicate may be compounded by atypical and idiosyncratic physical and psychological behavior, which makes pain assessment extremely difficult. It should be noted, however, that stimulus detection and pain threshold are preserved in Alzheimer's Disease, even though anticipation and autonomic reactivity are severely affected $^{38}$. A number of user-friendly observational instruments have been developed to measure pain in these patients, such as the Pain Assessment in Advanced Dementia Scale (PAINAD) and the Pain Assessment Checklist for Seniors with Limited Ability to Communicate (PACSLAC). The PAINAD consists of five items (breathing, negative vocalization, facial expression, body language and consolability) that are each scored from 0 to 2, giving a range of results from 0 (no pain) to 10 (severe pain). The four subscales of the PACSLAC cover: (i) social, personality and mood indicators, (ii) facial expressions, (iii) activity and body movement, and (iv) physiological and other factors, including eating, sleep changes and vocalizations. The observer marks 60 items that indicate subtle changes in behavior as being present or absent, and the total score appears to discriminate between painful, calm and distressing events ${ }^{39}$.

\section{Consensus point}

Standardized instruments can improve physician/ patient communication and understanding of the patient's pain experience.

\section{Painvision}

One innovative technology currently being developed in Belgium is Painvision. This utilizes the fact that facial expression is an important indicator of pain in patients with dementia, and that their facial responses are closely related to the intensity of noxious stimulation ${ }^{40}$. During normal nursing care, facial expressions are not continuously monitored and their interpretation is not objective. Painvision is a visual system consisting of two synchronized video recording cameras and a wi-fi computer network which can continually identify discomfort in real time, and will ultimately be able to alert a caregiver via the Internet ${ }^{41}$.

\section{Improving pain management in the elderly patient}

\section{General principles}

The widely accepted biopsychosocial model considers pain to be an interactive, psychophysiological behavior pattern that cannot be separated into distinct, independent psychosocial and physical components ${ }^{42}$. It therefore follows that a multidisciplinary approach is recommended to investigate all possible options for optimal management, including (1) pharmacotherapy, (2) psychological support, (3) physical rehabilitation, and (4) interventional procedures $^{34}$. A number of studies and reviews have shown this approach to be more effective than standard, non-multidisciplinary care in reducing pain and emotional distress, and improving function ${ }^{43-46}$. Ideally, multidisciplinary care should also involve the patient's family and any carers, and be adapted to the patient's individual needs. Particular caution should be exercised where the patient is being treated on an outpatient basis and lives alone. In this situation, the possible side effects of powerful analgesics and their consequences - must be taken into consideration. The absence of a carer or suitable family member may also limit the range of potential treatments; for example, transcutaneous electrical nerve stimulation (TENS) may be excluded if there is nobody to help attach the electrodes.

Pain is not a homogeneous sensory entity. Several distinct types exist which are produced by a range of mechanisms, including nociception, peripheral sensitization, central sensitization, ectopic excitability, structural reorganization and decreased inhibition ${ }^{47-50}$. The same painful symptom may be generated by a number of mechanisms, and a single mechanism can produce different symptoms, ranging from paresthesia to spontaneous burning pain ${ }^{51}$. Not all patients with chronic pain have similar mechanisms and intensity does not reflect the neurobiological causes, only the extent to which they are activated ${ }^{52}$. For pharmacological therapy, therefore, it is rational to use agents which address the likely causative mechanisms wherever possible. For example, the induction of cyclooxygenase-2 (COX-2) contributes substantially to the pain of most inflammatory conditions, so COX-2 inhibitors have a clear role here. However, these agents offer no benefit in diabetic peripheral neuropathy, where nerve injury leads to abnormal sodium channel activity and pain is mainly due to ectopic excitability ${ }^{53,54}$.

Psychological support aims to address anxiety, stress and depression by giving patients some control over their 
pain, and may include strategies such as psychotherapy, stress management, relaxation training, biofeedback and behavior modification. Counseling patients and educating them about their conditions and the anticipated outcomes can also prove valuable ${ }^{55}$. The aim of physical rehabilitation is to improve physical function and help the patient to live a more independent life. It may include such elements as physiotherapy, graded exercises, postural control, pacing strategies, and functional movement to improve motor control. It is strongly recommended by the American Society of Anesthesiologists for the relief of low back pain ${ }^{56}$. Interventional procedures - such as nerve blocks - can help the clinician to arrive at a precise diagnosis and may allow lower doses of medication to be prescribed ${ }^{34}$.

\section{Declining organ function}

Organ function progressively declines with the passage of time. Between 30 years and extreme old age, there are decreases of approximately $50 \%$ or more in vital capacity, glomerular filtration rate, renal plasma flow and maximal breathing capacity (Figure 1$)^{57}$. The function of the gastrointestinal, hemopoetic and immune systems also declines ${ }^{58,59}$. These physiological changes may affect drug metabolism ${ }^{60}$ and the risk of an adverse drug reaction is greater in elderly patients ${ }^{61}$. Drugs with anticholinergic activity may accelerate cognitive decline ${ }^{62}$. Opioids may be associated with a higher incidence of adverse events than previously thought, including cardiovascular events, acute kidney injury and fractures ${ }^{63}$, although the risk varies by opioid, adverse event and treatment duration ${ }^{64}$. Prescription is further complicated by the increasing interindividual variability in drug metabolism, drug action and adverse reactions that is a feature of advancing age, particularly when accompanied by frailty ${ }^{65}$. The clinician

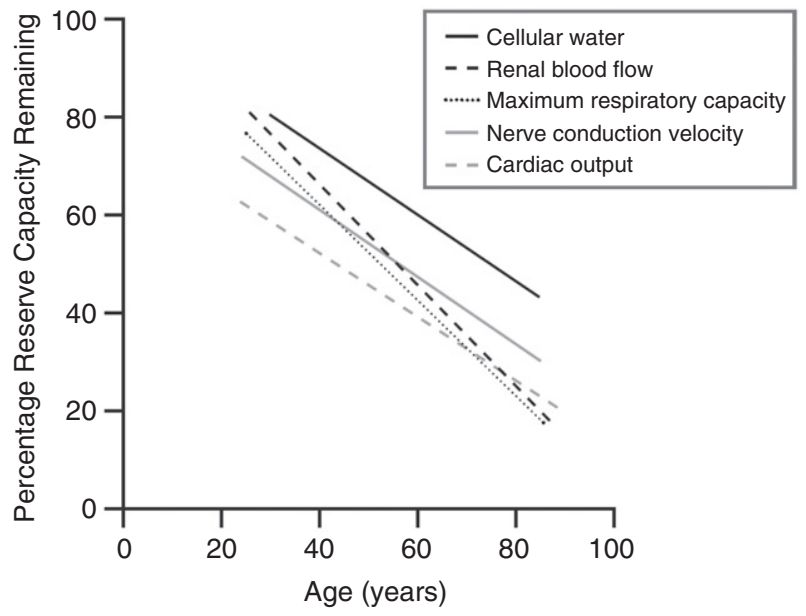

Figure 1. The decline in organ function with age. Adapted with permission from Fries $(2000)^{57}$ must take this altered physiology into account when assessing potential toxicity and response to treatment.

\section{Consensus point}

Physiological changes must be taken into account when prescribing drugs for elderly patients.

Pharmacokinetic changes include a reduction in renal and hepatic clearance and an increase in the volume of distribution of lipid-soluble drugs, which prolong the elimination of pharmaceutical agents ${ }^{66}$. Pharmacodynamic changes involve altered sensitivity to several classes of drugs, including anticoagulants, cardiovascular and psychotropic agents, which often increases their effect ${ }^{66}$ and the likelihood of side effects. Therefore, a lower than normal initial dose should be considered when prescribing a new medication to an elderly patient, together with less frequent dosing intervals and slow adjustment of the dosage to achieve the optimum therapeutic effect ${ }^{67,68}$. This approach can be summed up by the adage 'start low, go slow and follow up'. A long-term view with frequent monitoring and follow up is very important, to reassess the response to therapy and to avoid either overdosing or under-treatment.

\section{Consensus point}

The 'start low, go slow and follow up' approach should be considered when prescribing medication to elderly patients.

The least invasive route of administration should be used $^{69}$; the oral route may be the most convenient and it can rapidly provide relatively steady blood concentrations, but transdermal administration may be preferred for some patients. The advantages and disadvantages of the two routes (if available) should be routinely evaluated for each patient.

The application of technology can assist in clinical decisions regarding the dosage of drugs in individual patients. For example, computerized provider order entry $(\mathrm{CPOE})$ systems, where the prescriber personally enters the prescription into a computer and the prescription is then transmitted to the pharmacy ${ }^{70}$, can recommend the adjustment required to allow for impaired renal function.

Some classes of drugs should be used with extreme caution in elderly patients as a result of age-related changes. Because this age group is most likely to develop delirium, it is important to avoid drugs that might increase the risk of this adverse event. A literature review on the association between medications and delirium found that benzodiazepines, opioids, dihydropyridines and antihistamines 
appear to be associated with an increased risk of delirium, but concluded that in the case of opioids caution should be tempered with the observation that untreated severe pain can itself cause delirium ${ }^{71}$. In its revised guidelines for managing pain in older persons published in 2009, the American Geriatric Society recommends that non-steroidal anti-inflammatory drugs (NSAIDs) and COX-2 selective inhibitors "may be considered rarely, and with extreme caution, in highly selected individuals" ${ }^{69}$, citing their association with adverse events including gastrointestinal toxicity ${ }^{72}$ (which increases in frequency and severity with age ${ }^{73}$ ), and interference with renal function ${ }^{74,75}$. Furthermore, all patients taking these drugs should be routinely assessed for gastrointestinal and renal toxicity, hypertension, heart failure, and other drugdrug and drug-disease interactions ${ }^{69}$. Acetaminophen is recommended for patients with mild to moderate persistent pain, especially musculoskeletal pain, while opioid therapy should be considered for "all patients with moderate to severe pain, pain-related functional impairment or diminished quality of life due to pain"69.

When prescribing opioids, it should be borne in mind that with all these agents - except buprenorphine - the half-life of the active drug and metabolites is increased in the elderly and in patients with renal dysfunction ${ }^{76}$. It is therefore recommended that doses should be reduced, a longer time interval be used between doses, and creatinine clearance be monitored ${ }^{76}$. Thus buprenorphine appears to be the first-line choice for opioid treatment in the elderly. However, the fact that it is a partial agonist at the $\mu$-opioid receptor has implications for patients being switched to buprenorphine from a pure $\mu$-opioid agonist, such as morphine or oxycodone. If the switch is made abruptly, the patient may experience withdrawal symptoms such as sweating, anxiety, insomnia, tachycardia, nausea, abdominal cramps and muscle pains. To prevent this, a tapering schedule should be used; the dose of the pure $\mu$-opioid agonist is decreased by about $20-25 \%$ every day or two, while the dose of buprenorphine is simultaneously titrated upwards.

The opioid methadone requires special caution in elderly patients. Its analgesic effect lasts only 6 to 8 hours, which is much shorter than its half-life of 16 to 30 hours, so the repeated dose required for pain relief can result in accumulation of the drug in patients with reduced hepatic and renal function ${ }^{77}$.

Clinicians should also be aware that opioid use is associated with an increased risk of injury and fractures, which is dose-dependent and higher for short-acting opioids than long-acting opioids, especially during the first 2 weeks of therapy ${ }^{78-80}$. It is generally believed that the increased risk is a result of side effects such as dizziness, sedation, lightheadedness and nausea leading to a greater number of falls, but some researchers have suggested that opioids might also interfere with bone formation through suppression of endogenous sex hormone production ${ }^{81}$. Coanalgesics such as pregabalin, gabapentin and tricyclic antidepressants - which can themselves produce dizziness and sedation - may further compound the risk.

\section{Comorbidities and polypharmacy}

The presence of multiple comorbidities is particularly striking in those of very advanced age; $31 \%$ of patients aged $\geq 85$ years have $\geq 4$ chronic disorders ${ }^{82}$. To treat these, many elderly people receive polypharmacy, with the attendant risk of drug/drug interactions that increases exponentially with the number of medications taken ${ }^{83}$. It has been shown that about two-thirds of communitydwelling people aged $>60$ years take four or more medications daily, frail elderly people with multiple comorbidities take an average of nine ${ }^{84}$, and elderly hospital in-patients may be prescribed as many as fourteen ${ }^{83}$. The probability of interactions may be further increased by the consumption of over-the-counter (OTC) medications, which many patients perceive to be unimportant and do not disclose to their physician. One study of community-dwelling individuals aged 57 to 85 years found that $46 \%$ of those receiving at least one prescription drug were concurrently taking OTC medications, and 52\% were concurrently taking dietary supplements ${ }^{85}$. Thus it is important to be aware of all the medications that the patient is taking - including over-the-counter preparations - and the doses of each.

\section{Consensus point}

Polypharmacy is common in elderly patients, leading to an increased risk of drug/drug interactions and serious adverse events.

Interactions between drugs can lead to serious adverse events or a reduction in therapeutic effect. In pharmacodynamic interactions, two or more drugs directly influence each other's effects, whereas pharmacokinetic interactions involve the reciprocal influencing of absorption, distribution, metabolism and elimination, altering the effective concentration of the drugs at their sites of action ${ }^{86}$. Common drug/drug interactions in elderly patients include (i) aspirin with ibuprofen or naproxen, increasing the cardiac risk of patients with coronary heart disease, (ii) NSAIDs with angiotensin-converting enzyme (ACE) inhibitors giving elevated serum potassium levels and possible renal failure, or with COX-2 inhibitors, increasing the risk of gastrointestinal bleeding, and iii) combinations of drugs acting on the CNS, leading to sedation, confusion and falls ${ }^{86,87}$.

To minimize the risk of interaction with multiple medications and serious adverse events, both the route of administration and the specific agents prescribed should 
be considered. In some circumstances, the slow increase in serum concentration offered by transdermal administration of fentanyl or buprenorphine may be advantageous; for example, the time to minimum therapeutic concentration of transdermal buprenorphine is 21 hours $^{88}$. This route avoids wide variations in drug concentration, which are less well tolerated by elderly patients, in line with World Health Organization guidelines. Of particular relevance to this age group, it offers ease of application and can be used when elderly patients are unable to tolerate, or unwilling to swallow, oral medication. However, care must be taken not to initiate treatment at too high a dose ${ }^{89}$, as this can increase the likelihood of serious adverse events, especially in patients who are opioid-naïve.

Before initiating pharmacological treatment, a thorough assessment of all medications should be conducted and an effort made to reduce the number, if possible ${ }^{90}$. When prescribing a particular class of analgesic, it may be possible to reduce the risk of subsequent drug/drug interactions by matching the specific agent to the patient's physiology and existing medication. For example, agerelated decline in cytochrome P-450 function may increase the risk of toxic interactions; selective serotonin reuptake inhibitors (SSRIs) inhibit the cytochrome system and can lead to an accumulation of narcotic agents if the two drugs are administered concurrently ${ }^{34}$. For example, tramadol is partly a prodrug, its analgesic action depending on both the parent drug and the M1 metabolite (O-desmethyltramadol). If demethylation of the parent drug via the cytochrome P-450 system is decreased by simultaneous administration of an SSRI, then analgesia may be reduced and the parent drug can accumulate. As the combined serotonergic activity of tramadol and the SSRI may be at least additive, the risk of a potentially fatal serotonin syndrome is increased. If an opioid is required and the current drug regime indicates a possible cytochrome P-450 interaction, then morphine, hydromorphone, oxymorphone or tapentadol should be considered, because these are not metabolized by the cytochrome P-450 system. For tapentadol, no clinically relevant drug-drug interactions are likely to occur through induction or inhibition of cytochrome P450 enzymes or plasma protein binding ${ }^{91}$. If the glomerular filtration rate is reduced, however, then buprenorphine is an attractive option as it is excreted mainly via the liver, avoiding potentially high serum levels of opioid $^{76}$.

\section{Adherence/compliance}

Estimates of the extent of non-adherence in the elderly vary from $40 \%$ to $75 \%$ and there are three common forms $^{92}$. Some older patients take more than the prescribed dose in the mistaken belief that this will have a greater beneficial effect. Forgetting to take a dose is common, particularly when there is cognitive decline or the patient has been prescribed multiple medications. Most frequent is under-use; inappropriate drug discontinuation may occur in up to $40 \%$ of patients, particularly within the first year of a chronic care regimen ${ }^{92}$.

Various strategies can be used to improve adherence in elderly patients. Communication between physician and patient should be optimized as far as possible to enable educational interventions. Where the patient is living in the community, it is important to involve any caregivers and the patient's family in the provision of practical support, providing relations within the family are good. Adherence is 1.74 times better in patients from cohesive families, but 1.53 times worse when the family is in conflict $^{93}$.

\section{Consensus point}

It is important to involve any caregivers and the patient's family in the provision of practical support, providing that relations within the family are good.

Emphasizing the value of the drug regimen and the benefit of adherence has been shown to be effective in improving adherence $^{94}$. In one study of elderly patients leaving hospital, by 12 weeks after discharge half the patients were initially taking fewer than half the prescribed tablets, and a further quarter were seriously overdosing themselves ${ }^{95}$. However, a 15 minute counseling session was found to be highly effective in reducing medication errors, even in confused patients ${ }^{95}$. The patient should be provided with clear instructions and the dosing regimen simplified as far as possible; for example, by using drugs with longer half-lives to reduce the number of medications and facilitate daily dosing, and by customizing the timing of doses to match the patient's lifestyle ${ }^{96}$. The use of medicationtaking systems (e.g. pill-boxes) to organize daily doses can reduce errors, while the attendance of communitybased patients (and thus adherence) can be improved by making clinical appointments as convenient and efficient for them as possible ${ }^{96}$. With the increasing integration of technology into patient care and society in general, the sending of daily text messages to remind patients to take medication has been shown to improve adherence rates in healthy young women using oral contraceptives ${ }^{97}$, and this method may be transferable to elderly patients.

Elderly patients are more vulnerable to medicationrelated problems than younger ones, because of the dosage adjustment required by pharmacokinetic and pharmacodynamic changes, as well as the presence of comorbidities and polypharmacy ${ }^{67}$. The majority of medication errors are preventable ${ }^{98}$. Most are due to prescribing faults (failure in deciding the correct drug to use and how) or prescription errors (providing incorrect instructions), and 
one way of reducing the number is by the application of technology. CPOE systems not only guarantee legibility and avoidance of transcription errors, they can also ensure the completeness and accuracy of prescriptions ${ }^{99}$. In studies, CPOE has decreased the incidence of medication errors by $\geq 55 \%{ }^{100}$ and $95.9 \%{ }^{101}$. A similar benefit (>90\% reduction in dispensing errors) has been achieved by introducing a barcode-enabled point-of-care (BPOC) system $^{102}$. This involves scanning a patient's barcoded wristband and the barcode on the intended individual drug dose. Relevant patient information is then displayed on a laptop computer, which also compares the proposed dose with the patient's drug regimen - in the event of any mismatch, an alert appears on the screen.

\section{Education}

For the various measures outlined above to be widely implemented, there needs to be an improvement in the teaching of pain medicine. For example, opioids remain the drugs of choice for the treatment of moderate to severe pain ${ }^{103}$, but the appropriate use of these agents is often restricted by barriers such as a fear of abuse and addiction, particularly in developing countries ${ }^{103}$. Misconceptions held by healthcare professionals are often a major factor in the under-use of opioids. There are widespread concerns about opioid addiction, tolerance and hyperalgesia, as well as unrealistic anxieties about precipitating adverse side effects and an unfounded assumption that long-term opioid treatment necessarily impairs patients' quality of life $^{103}$. This should not be altogether surprising, as physicians responding to surveys acknowledge that they have received insufficient training in opioid pharmacology and pain management in general ${ }^{104,105}$. The need for improved training is even more marked in the case of elderly patients, where accurate diagnosis and the satisfactory management of pain present particular challenges, and require higher levels of expertise.

Firstly, there should be a greater emphasis on pain management in the medical undergraduate curriculum. For example, the median time spent on pain management by a UK medical student is 13 hours, and in some cases as little as 6 hours $^{106}$. Furthermore, the subject is taught piecemeal and not as a separate module ${ }^{106}$. Continuing medical education (CME), such as the PAIN EDUCATION Program offered as part of the CHANGE PAIN initiative, also has a vital role to play. Currently, six CME modules have been developed - on topics such as mechanisms of pain and the multimodal management of chronic pain - and are available online in several European languages. They are accredited by the Union Européenne des Médecins Spécialistes (UEMS) and various national bodies. A new module dealing specifically with pain in the elderly is almost complete, and will soon be available from the CHANGE PAIN website (http://www.change-pain.com).

\section{Conclusions}

Many elderly people have chronic pain, but studies have consistently shown high levels of untreated or under-treated pain in older people which adversely affects their quality of life. The reasons for this include the failure by patients to report pain and the misconception among some healthcare professionals that the elderly have a reduced perception of pain. Also, pain management is often challenging in these patients because of declining organ function, impaired cognition, the presence of comorbidities, increased vulnerability to side effects, and polypharmacy. In the developed world, the proportion of elderly people in the population has risen dramatically in recent years and this is expected to continue, so the need to improve pain management for this age group is becoming increasingly urgent.

A number of different approaches could prove beneficial. Standardized instruments can improve communication and help diagnose patients' pain. A 'start low, go slow and follow up' approach should be considered when prescribing medications to elderly patients. The number of prescribing faults and prescription errors can be reduced by the introduction of technology, such as CPOE and BPOC systems. Non-adherence levels in elderly patients are currently high, but these could be improved by counseling on the benefits of treatment, simplifying dosage regimens, and utilizing medication-taking systems.

Finally, in order to increase awareness among the medical community of how pain management can be improved, there needs to be better teaching of pain medicine - particularly with respect to the use of opioids - both at undergraduate level and post-qualification.

\section{Transparency}

\section{Declaration of funding}

Funding for this study was provided by Grünenthal GmbH.

\section{Declaration of financial/other relationships}

All authors are members of the CHANGE PAIN International Advisory Board. As such, they have received honoraria for attending the meetings upon which this paper is based. In addition, H.-G.K. and G.M.-S. declare that they are chairmen of the International Advisory Board on CHANGE PAIN for Grünenthal $\mathrm{GmbH}$, and receive honoraria in this context. None of the authors received honoraria for the writing of this paper.

$\mathrm{CMRO}$ peer reviewers may have received honoraria for their review work. The peer reviewers on this manuscript have disclosed that they have no relevant financial relationships. 


\section{Acknowledgments}

Medical writing support was provided by Derrick Garwood of Derrick Garwood Ltd, Cambridge, UK, and was funded by Grünenthal GmbH.

\section{References}

1. Pearce D. The demographic situation in the European Union. Population Trends 2001;104:6-11

2. European Commission. Population projections 2008-2060. Available at: http://europa.eu/rapid/press-release_STAT-08-119_en.htm [Last accessed 15 October 2013]

3. Administration on Aging. A Profile of Older Americans: 2009. U.S. Department of Health and Human Services. Available at: http://www.aoa.gov/aoaroot/ aging_statistics/profile/2009/docs/2009profile_508.pdf [Last accessed 2 April 2013]

4. WP 2. Analysis of Needs. Final Report. 2010 Nurse Managed Care for Elderly Project Team, 2010. Available at: http://www.nmce.eu/images/stories/ articles/analysis_of_needs_en.pdf [Last accessed 3 April 2012]

5. Elliott AM, Smith BH, Penny Kl, et al. The epidemiology of chronic pain in the community. Lancet 1999;354:1248-52

6. Dieleman JP, Kerklaan J, Huygen FJ, et al. Incidence rates and treatment of neuropathic pain conditions in the general population. Pain 2008:137:681-8

7. Bergh I, Steen $G$, Waern M, et al. Pain and its relation to cognitive function and depressive symptoms: a Swedish population study of 70-year-old men and women. J Pain Symp Manag 2003;26:903-12

8. Rao A, Cohen HJ. Symptom management in the elderly cancer patient: fatigue, pain, and depression. J Natl Cancer Inst Monogr 2004;32:150-7

9. Robinson CL. Relieving pain in the elderly. Health Prog 2007;88:48-53

10. Gianni W, Madaio RA, Di Cioccio L, et al. Prevalence of pain in elderly hospitalized patients. Arch Gerontol Geriatr 2010;51:273-6

11. Cassel KC. Geriatric medicine: an evidence-based approach. New York, USA: Springer, 2003

12. Abdulla $\mathrm{A}$, Adams N, Bone $\mathrm{M}$, et al. Guidance on the management of pain in older people. Age Ageing 2013;42:11-57

13. Smith AK, Cenzer IS, Knight SJ, et al. The epidemiology of pain during the last 2 years of life. Ann Intern Med 2010;153:563-9

14. Gormsen L, Rosenberg R, Bach FW, et al. Depression, anxiety, health-related quality of life and pain in patients with chronic fibromyalgia and neuropathic pain. Eur J Pain 2010;14:127.e1-8

15. Apkarian AV, Sosa Y, Krauss BR, et al. Chronic pain patients are impaired on an emotional decision-making task. Pain 2004;108:129-36

16. Baliki MN, Chialvo DR, Geha PY, et al. Chronic pain and the emotional brain: specific brain activity associated with spontaneous fluctuations of intensity of chronic back pain. J Neurosci 2006;26:12165-73

17. Apkarian AV, Sosa Y, Sonty S, et al. Chronic back pain is associated with decreased prefrontal and thalamic gray matter density. J Neurosci 2004:24:10410-15

18. Breivik H, Collett B, Ventafridda V, et al. Survey of chronic pain in Europe: prevalence, impact on daily life, and treatment. Eur J Pain 2006;10:287-333

19. Fishbain DA, Cutler RB, Cole B, et al. Are patients with chronic low back pain or chronic neck pain fatigued? Pain Med 2004;5:187-95

20. Green BH, Copeland JR, Dewey ME, et al. Risk factors for depression in elderly people: A prospective study. Acta Psychiatr Scand 1992;86:213-17

21. Phillips JM, Gatchel RJ. Extraversion-introversion and chronic pain: locus of control in the patient with chronic pain. In: Gatchel R, Weisberg J (eds). Personality Characteristics of Patients with Pain. Washington DC: American Psychological Association, 2000:181-202

22. Kantar Health Inc. National Health And Wellness Survey, 2010 [EU]. Princeton, NJ, USA, 2010

23. Leadley RM, Armstrong $\mathrm{N}$, Reid $\mathrm{KJ}$, et al. Healthy aging in relation to chronic pain and quality of life in Europe. Pain Pract 2013: published online 21 October 2013, doi:10.1111/papr.12125
24. AGS Panel on Persistent Pain in Older Persons. The management of persistent pain in older persons. J Am Geriatr Soc 2002;50(6 Suppl):S205-24

25. Iyer PW. Medical-legal aspects of pain and suffering. Tucson, Arizona: Lawyers \& Judges Publishing Company Inc., 2005

26. Mäntyselkä PT, Turunon JHO, Ahonen RS, et al. Chronic pain and poor selfrated health. J Am Med Assoc 2003;290:2435-42

27. Mostofsky DI, Lomranz J. Handbook of pain and aging. Basel, Switzerland: Birkhäuser, 1997

28. Leong IY, Farrell MJ, Helme RD, et al. The relationship between medical comorbidity and self-rated pain, mood disturbance, and function in older people with chronic pain. J Gerontol A Biol Sci Med Sci 2007:62:550-5

29. Scherder EJA, Sergeant JA, Swaab DF. Pain processing in dementia and its relation to neuropathology. Lancet Neurol 2003;2:677-86

30. Morrison RS, Siu AL. A comparison of pain and its treatment in advanced dementia and cognitively intact patients with hip fracture. J Pain Symptom Manage 2000;19:240-8

31. Mäntyselkä P, Hartikainen S, Louhivuori-Laako K, et al. Effects of dementia on perceived daily pain in home-dwelling elderly people: a population-based study. Age Ageing 2004;33:496-9

32. Schilling ML. Pain management in older adults. Curr Psychiatry Rep 2003;5:55-61

33. Rief $\mathrm{W}$, Kaasa $\mathrm{S}$, Jensen $\mathrm{R}$, et al. New proposals for the International Classification of Diseases-11 revision of pain diagnoses. J Pain 2012;13:305-16

34. Kaye AD, Baluch A, Scott JT. Pain management in the elderly population: a review. Ochsner J 2010;10:179-87

35. Baron R, Binder A, Wasner G. Neuropathic pain: diagnosis, pathophysiological mechanisms, and treatment. Lancet 2010;9(8):807-19

36. Melzack R. The McGill Pain Questionnaire: major properties and scoring methods. Pain 1975:1:277-99

37. Müller-Schwefe G, Jaksch W, Morlion B, et al. Make a CHANGE: optimising communication and pain management decisions. Curr Med Res Opin 2011:27:481-8

38. Benedetti F, Arduino C, Vighetti S, et al. Pain reactivity in Alzheimer patients with different degrees of cognitive impairment and brain electrical activity deterioration. Pain 2004;111:22-9

39. Zwakhalen SMG, Hamers JPH, Abu-Saad HH, Berger MPF. Pain in elderly people with severe dementia: a systematic review of behavioural pain assessment tools. BMC Geriatrics 2006;6:3. doi:10.1186/1471-2318-6-3

40. Kunz M, Scharmann S, Hemmeter U, et al. The facial expression of pain in patients with dementia. Pain 2007:133:221-8

41. Painvision. Monitoring of discomfort in demented elderly patients based on automatic image recognition. Available at: http://project.mobilab.be/painvision/index.html. [Last accessed 7 May 2012]

42. Turk DC, Monarch ES. Biopsychosocial perspective on chronic pain. In: Turk DC, Gatchel RJ (Eds). Psychological Approaches to Pain Management: A Practitioner's Handbook. New York, USA: Guilford, 2002

43. Guzman J, Esmail $\mathrm{R}$, Karjalainen $\mathrm{K}$, et al. Multidisciplinary rehabilitation for chronic low back pain: a systematic review. BMJ 2001;332:1511-16

44. Scascighini L, Toma V, Dober-Spielmann S, et al. Multidisciplinary treatment for chronic pain: a systematic review of interventions and outcomes. Rheumatology 2008;47:670-8

45. Gatchel RJ, McGeary DD, Peterson A, et al. Preliminary findings of a randomized controlled trial of an interdisciplinary military pain program. Mil Med 2009; $174: 270-7$

46. Roditi D, Robinson ME. The role of psychological interventions in the management of patients with chronic pain. Psychol Res Behav Manag 2011:4:41-9

47. Mogil JS, Yu I, Busbaum Al. Pain genes?: natural variation and transgenic mutants. Annu Rev Neurosci 2000;23:777-811

48. Woolf CJ, Salter MW. Neuronal plasticity: increasing the gain in pain. Science 2000;288:1765-9

49. Julius D, Basbaum Al. Molecular mechanisms of nociception. Nature $2001: 413 \cdot 203-10$ 
50. Scholz J, Woolf CJ. Can we conquer pain? Nat Neurosci 2002; 5(Suppl):1062-7

51. Woolf CJ, Max MB. Mechanism-based pain diagnosis: issues for analgesic drug development. Anesthesiol 2001;95:241-9

52. Woolf CJ. Pain: moving from symptom control toward mechanism-specific pharmacologic management. Ann Intern Med 2004;140:441-51

53. Bierhaus A, Fleming T, Stoyanov S, et al. Methylglyoxal modification of $\mathrm{Na}_{v} 1.8$ facilitates nociceptive neuron firing and causes hyperalgesia in diabetic neuropathy. Nat Med 2012;18:926-34

54. Zenker J, Ziegler D, Chrast R. Novel pathogenic pathways in diabetic neuropathy. Trends Neurosci 2013;36:439-49

55. Thieme K, Turk DC, Flor H. Responder criteria for operant and cognitivebehavioral treatment of fibromyalgia syndrome. Arthritis Rheum 2007;57: 830-6

56. Practice Guidelines for Chronic Pain Management. An updated report by the American Society of Anesthesiologists Task Force On Chronic Pain Management and the American Society of Regional Anesthesia and Pain Medicine. Anesthesiology 2010;112:1-24

57. Fries JF. Compression of morbidity in the elderly. Vaccine 2000;18:1584-9

58. Blechman MB, Gelb AM. Aging and gastrointestinal physiology. Clin Geriatr Med 1999;15:429-38

59. Gazit R, Weissman IL, Rossi DJ. Hematopoietic stem cells and the aging hematopoietic system. Semin Hematol 2008;45:218-24

60. Klotz U. Pharmacokinetics and drug metabolism in the elderly. Drug Metab Rev 2009;41:67-76

61. Bressler R, Bahl JJ. Principles of drug therapy for the elderly patient. Mayo Clin Proc 2003;78:1564-77

62. Fox C, Livingston G, Maidment ID, et al. The impact of anticholinergic burden in Alzheimer's Dementia - the Laser-AD study. Age Ageing 2011;40:730-5

63. Solomon DH, Rassen JA, Glynn RJ, et al. The comparative safety of analgesics in older adults with arthritis. J Am Med Assoc 2010;170:1968-78

64. Solomon DH, Rassen JA, Glynn RJ, et al. The comparative safety of opioids for nonmalignant pain in older adults. Arch Intern Med 2010;170:1979-86

65. Kinirons MT, O'Mahony MS. Drug metabolism and ageing. Br J Clin Pharmacol 2004;57:540-4

66. Mangoni AA, Jackson SHD. Age-related changes in pharmacokinetics and pharmacodynamics: basic principles and practical applications. $\mathrm{Br} \mathrm{J}$ Clin Pharmacol 2004:57:6-14

67. Tobias DE. Start low and go slow. Hospital Pharmacist 2003;38:634-6

68. Nakasato Y, Young RL. Geriatric rheumatology: a comprehensive approach. New York: Springer-Verlag, 2011

69. American Geriatrics Society Panel on the Pharmacological Management of Persistent Pain in Older Patients. Pharmacological management of persistent pain in older patients. J Am Geriatr Soc 2009;57:1331-46

70. Devine EB, Hansen RN, Wilson-Norton JL, et al. The impact of computerized provider order entry on medication errors in a multispecialty group practice. J Am Med Inform Assoc 2010;17:78-84

71. Clegg A, Young JB. Which medications to avoid in people at risk of delirium: a systematic review. Age Ageing 2011;40:23-9

72. Ofman JJ, MacLean $\mathrm{CH}$, Straus $\mathrm{WL}$, et al. A metaanalysis of severe upper gastrointestinal complications of nonsteroidal antiinflammatory drugs. J Rheumatol 2002;29:804-12

73. Boers M, Tangelder MJD, van Ingen $\mathrm{H}$, et al. The rate of NSAID-induced endoscopic ulcers increases linearly but not exponentially with age: a pooled analysis of 12 randomised trials. Ann Rheum Dis 2007;66:417-18

74. Niccoli L, Bellino S, Cantini F. Renal tolerability of three commonly employed non-steroidal anti-inflammatory drugs in elderly patients with osteoarthritis. Clin Exp Rheumatol 2002;20:201-7

75. Juhlin T, Björkman S, Höglund P. Cyclooxygenase inhibition causes marked impairment of renal function in elderly subjects treated with diuretics and ACE-inhibitors. Eur J Heart Fail 2005;7:1049-56

76. Pergolizzi J, Böger Rh, Budd K, et al. Opioids and the management of chronic severe pain in the elderly: consensus statement of an international expert panel with focus on the six clinically most often used World Health
Organization Step III opioids (buprenorphine, fentanyl, hydromorphone, methadone, morphine, oxycodone). Pain Pract 2008:8:287-313

77. King SA. Chronic pain management in the elderly: an update on safe, effective options. Consultant360 2012;52(5). Available at: http://www. consultant360.com/article/chronic-pain-management-elderly-update-safeeffective-options [Last accessed 11 February 2014]

78. Saunders KW, Dunn KM, Merrill JO, et al. Relationship of opioid use and dosage levels to fractures in older chronic pain patients. J Gen Intern Med 2010;25:310-15

79. Buckeridge D, Huang A, Hanley J, et al. Risk of injury associated with opioid use in older adults. J Am Geriatr Soc 2010;58:1664-70

80. Miller M, Stürmer $\mathrm{T}$, Azrael $\mathrm{D}$, et al. Opioid analgesics and the risk of fractures in older adults with arthritis. J Am Geriatr Soc 2011:59:430-8

81. Kinjo M, Setoguchi S, Schneeweiss $\mathrm{S}$, et al. Bone mineral density in subjects using central nervous system-active medications. Am J Med 2005; 118:1414.e7-12

82. Wolff JL, Starfield B, Anderson G. Prevalence, expenditures, and complications of multiple chronic conditions in the elderly. Arch Intern Med 2002;162:2269-76

83. Köhler Gl, Bode-Böger SM, Busse R, et al. Drug-drug interactions in medical patients: effects of in-hospital treatment and relation to multiple drug use. Int J Clin Pharmacol Ther 2000;38:504-13

84. Elliott RA. Problems with medication use in the elderly: an Australian perspective. J Pharm Prac Res 2006;36:58-66

85. Qato DM, Alexander GC, Conti RM, et al. Use of prescription and overthe-counter medications and dietary supplements among older adults in the U.S. JAMA 2008;300:2867-78

86. Cascorbi I. Drug interactions - principles, examples and clinical consequences. Dtsch Arztebl Int 2012;109:546-56

87. Fendrick M, Pan DE, Johnson DE. OTC analgesics and drug interactions: clinical implications. Osteopath Med Prim Care 2008;2:2. doi:10.1186/ 1750-4732-2-2

88. Vadivelu N, Hines RL. Management of chronic pain in the elderly: focus on transdermal buprenorphine. Clin Interv Aging 2008:3:421-30

89. Botterman J, Criel N. Inappropriate use of high doses of transdermal fentanyl at admission to a palliative care unit. Palliat Med 2011:25:111-16

90. Lynch T. Management of drug-drug interactions: considerations for special populations - focus on opioid use in the elderly and long term care. Am J Manag Care 2011:17:S293-8

91. Kneip $\mathrm{C}$, Terlinden $\mathrm{R}$, Beier $\mathrm{H}$, et al. Investigations into the drug-drug interaction potential of tapentadol in human liver microsomes and fresh human hepatocytes. Drug Metab Lett 2008;2:67-75

92. Salzman C. Medication compliance in the elderly. J Clin Psychiatry 1995;56(Suppl 1):18-22

93. DiMatteo MR. Social support and patient adherence to medical treatment: a meta-analysis. Health Psychol 2004;23:207-18

94. Patton K, Meyers J, Lewis BE. Enhancement of compliance among patients with hypertension. Am J Manag Care 1997;3:1693-8

95. MacDonald ET, MacDonald JB, Phoenix M. Improving drug compliance after hospital discharge. Br Med J 1977;2:618-21

96. Osterberg L, Blaschke T. Adherence to medication. N Engl J Med 2005:353:487-97

97. Castaño PM, Bynum JY, Andrés R, et al. Effect of daily text messages on oral contraceptive continuation: a randomized controlled trial. Obstet Gynecol 2012;119:14-20

98. Picone DM, Titler MG, Dochterman J, et al. Predictors of medication errors among elderly hospitalized patients. Am J Med Qual 2008;23:115-27

99. Dennison RD. Creating an organizational culture for medication safety. Nurs Clin N Am 2005;40:1-23

100. Bates DW, Leape LL, Cullen DJ, et al. Effect of computerized physician order entry and a team intervention on prevention of serious medication errors. JAMA 1998:280:1311-16

101. Potts AL, Barr FE, Gregory DF, et al. Computerized physician order entry and medication errors in a pediatric critical care unit. Pediatrics 2004:113:59-63 
102. Poon EG, Cina JL, Churchill W, et al. Medication dispensing errors and potential adverse drug events before and after implementing bar code technology in the pharmacy. Ann Intern Med 2006;145:426-34

103. Brennan F, Carr DB, Cousins M. Pain management: a fundamental human right. Anesth Analg 2007;105:205-21

104. Von Roenn JH, Cleeland CS, Gonin R, et al. Physician attitudes and practice in cancer pain management: a survey from the Eastern Cooperative Oncology Group. Ann Intern Med 1993;19:121-6
105. Vainio A. Treatment of terminal care pain in France: a questionnaire study. Pain 1995;62:155-62

106. Survey of undergraduate pain curricula for healthcare professionals in the United Kingdom: a short report. The Pain Education Special Interest Group of the British Pain Society. London, UK: The British Pain Society, 2009. Available at: http://www.britishpainsociety.org/ members_sig_edu_short_report_survey.pdf [Last accessed 8 May 2012] 